8,500 megacuries. If this were 1 per cent of the world's effluent and it all became uniformly mixed in the sea (of a total volume $1.4 \times 10^{24}$ c.c.), the concentration would be $6 \times 10^{-7}$ microcuries per c.c., which is about the permissible activity for drinking water. The sea already contains $3 \times 10^{5}$ megacuries in the form of radioactive potassium, hence there should be no danger if the active effluent is uniformly mixed. Unfortunately, mixing in the sea is subject to weather conditions and there may be 'hot' spots of dangerous activity.

The biological hazards from the fission products depend largely on their chemical and physical states. Iodine, for example, is very important biologically because of its concentration in the thyroid; but it is not a serious problem in routine operations as it decays in a short time. In accidents or bombs, however, it may become a danger if it is deposited in the fall-out. In the Monte Bello test the fall-out contained water-soluble iodine, which was taken up in the thyroid of guinea pigs.

Of the other fission products, cæsium behaves like sodium; it is difficult to precipitate and would be expected to be found in water effluent. Tests for its presence in seaweed are being carried out. Barium and strontium, which are relatively soluble, are deposited in bone. The other elements are relatively insoluble in water or the digestive tract, but may be deposited on the lining of the gut.

The activity ingested by domestic animals is also of importance. The fresh vegetable diet consumed by man is small and its radioactivity has a chance to decay in storage. Animals, however, eat large quantities of grass, and superficial contamination of the earth presents an internal hazard to the animal and, consequently, to man eating the meat. The safeguard is again the time factor, and that most of the activity is deposited in bone.

Man receives a relatively larger intake through the lungs than through the alimentary tract. Most of the particles are, however, large enough to be caught up in the filter system of the upper respiratory tract, from which they are finally conveyed to the gut. The most important thing, therefore, is to keep the air clean and uncontaminated. Clean air ensures clean soil, vegetation and water supplies. Use of the sea as a disposal ground must be controlled to avoid contamination of edible fish. The ocean deeps may be a suitable dump for concentrated sources until technical improvements in propulsion make it possible to discharge them to interplanetary space.

\section{UNESCO ADVISORY COMMITTEE ON ARID ZONE RESEARCH}

\section{SESSION IN MONTPELLIER}

$\mathrm{T}$ HE Advisory Committee on Arid Zone Research, which is a Committee of the United Nations Educational, Scientific and Cultural Organization, held its sixth session in Montpellier during November $3-6,1953$, and the following are the principal recommendations that were made to the Director-General of Unesco.

Symposia. The holding of symposia should be continued, and, when possible, half of them should be jointly organized with other relevant agencies or scientific organizations so as to achieve closer liaison with them. The Director-General, it is suggested, should accept the invitation of the Indian Government to hold a symposium on "Wind and Solar Energy in Arid Areas" this autumn. Also, the subject for the symposium to be held in 1956 should be the formation and erosion of soils as affected by climatic factors, and this should, if possible, be held jointly with the Food and Agriculture Organization and the World Health Organization.

Review reports. It was decided at the session that review reports should be fewer in number and that they should deal with research subjects rather than consist of surveys of specific geographical areas. Each report ought to be a critical appreciation of work done and not merely a summary of publications. The reports should be published in book form, and, when a symposium is held on the same subject, they should be published, if possible, with its proceedings. The recommendation was made that six reports be obtained dealing with human and animal ecology in arid regions, two being on human ecology and one each on the ecology of mammals, birds, locusts and other insects.

Arid zone fellowships. Candidates selected for such fellowships should be of sufficient seniority and training to obtain adequate benefit, and careful consideration must be given not only as to the best location for the Fellow to work but also as to the person responsible for his studies and the length of his stay in each locality. Each Fellow should submit both interim and final reports on his work to the Committee.

Research projects. The Committee recommended the following procedure to be adopted in the submission of research projects to Unesco, and for their consideration by the Committee. (1) Projects should be submitted after examination by, and with the support of, the national commission of the member State from which it originates. Information should be provided about the suitability of the applicant to conduct or. supervise the work, and where relevant as to the relation of the project to other research. If the applicant is a member of a scientific institute, this institute should also give its support. (2) If it feels this desirable, Unesco should obtain further expert advice on the project from among its honorary consultants prior to submitting the proposal to the Advisory Committee. (3) Recipients of Unesco research grants must submit by March 1 and September 1 progress reports for the information of the Advisory Committee. Failure to submit such reports may involve the discontinuance of Unesco support. (4) The Advisory Committee should review current projects and should consider whether to advise continued support for them, before giving advice on the support of new projects.

The Committee also recommended that three criteria should guide the acceptance of projects submitted : the project must directly relate to a specific arid zone problem; it should bear on some principle of general scientific interest; and it should either be of a nature that can be expected to yield results within a period of two years, or be one that can be continued by local support, after initial financial aid from Unesco.

Unesco Symposium of Plant Ecology of the Arid Zone. Following the session of the Committee, a symposium organized by Unesco as part of its arid 
zone programme was held during November 7-10 in Montpellier with the help and support of the university there. Speakers from fifteen countries contributed papers under the following sections. (A) Structural and physiological features of the vegetation. This section included papers on ecological classification, the fodder value of desert plants in South Africa, and the effects of land management on arid zone vegetation. (B) Climatic, ecoclimatic and hydrological effects on vegetation. The papers in this section dealt not only with effects of rain and other climatic factors but also with dew measurement and with forests in arid areas. (C) Soil and vegetation. This section covered the effects of soil type, the influence of minor elements and soil microbiology. (D) Influence of other factors. These included overgrazing and soil insects, and a valuable account was given of methods used in Australia in land-use surveys. The symposium as a whole included a number of valuable papers. and provoked keen discussion. Its proceedings will be published.

\section{NEW CHEMICAL LABORATORIES OF THE UNIVERSITY OF SHEFFIELD}

$\mathrm{T}$

HE new chemical laboratories of the University of Sheffield were opened on February 5 by the Earl of Scarbrough, and afterwards honorary degrees were conferred upon Sir Cyril N. Hinshelwood, Prof. C. K. Ingold and Mr. T. A. MeKenna. A single structure now takes the place of laboratories that were formerly separated from one another and from the central stores by a hundred yards horizontally and as many feet vertically in a building without lifts. While the greater part of the cost has been met by grants to the University for that purpose by the University Grants Committee, the Staveley Coal and Iron and the Staveley Iron and Chemical Companies, in response to the appeal for a University Development Fund in 1947, covenanted to contribute a sum of $£ 50,000$ primarily for the benefit of the Chemistry Department. In permanent record of the University's appreciation, the research laboratories in the new Department have been named the Staveley Laboratories.

As the first stage of a larger structure which will be necessary for any significant increase in the present number of students, it consists of a main block facing Brook Hill, with a wing at its eastern end receding obliquely from the street. Provision has been made for additions when necessary at both ends of the block. The four-story building is of steel-framed brick faced with Portland stone; the sloping site allows unrestricted natural lighting to the lowest floor of the wing. The wing consists essentially of four large teaching laboratories, one above the other. From the lowest floor upwards, they are for intermediate classes, advanced inorganic chemistry, physical chemistry and elementary organic chemistry, respectively; each is served by a substore connected to the main store by a goods lift. These teaching laboratories have small rooms attached for special purposes, and in addition there are eight research laboratories and seven small rooms for lecturers.

The various floors are united by staircases at each end of the main block and an emergency staircase at the far end of the wing. There is a passenger lift at the junction of the main block and the wing, and provision has been made for another lift at the west end. The junction of the wing and main block, with

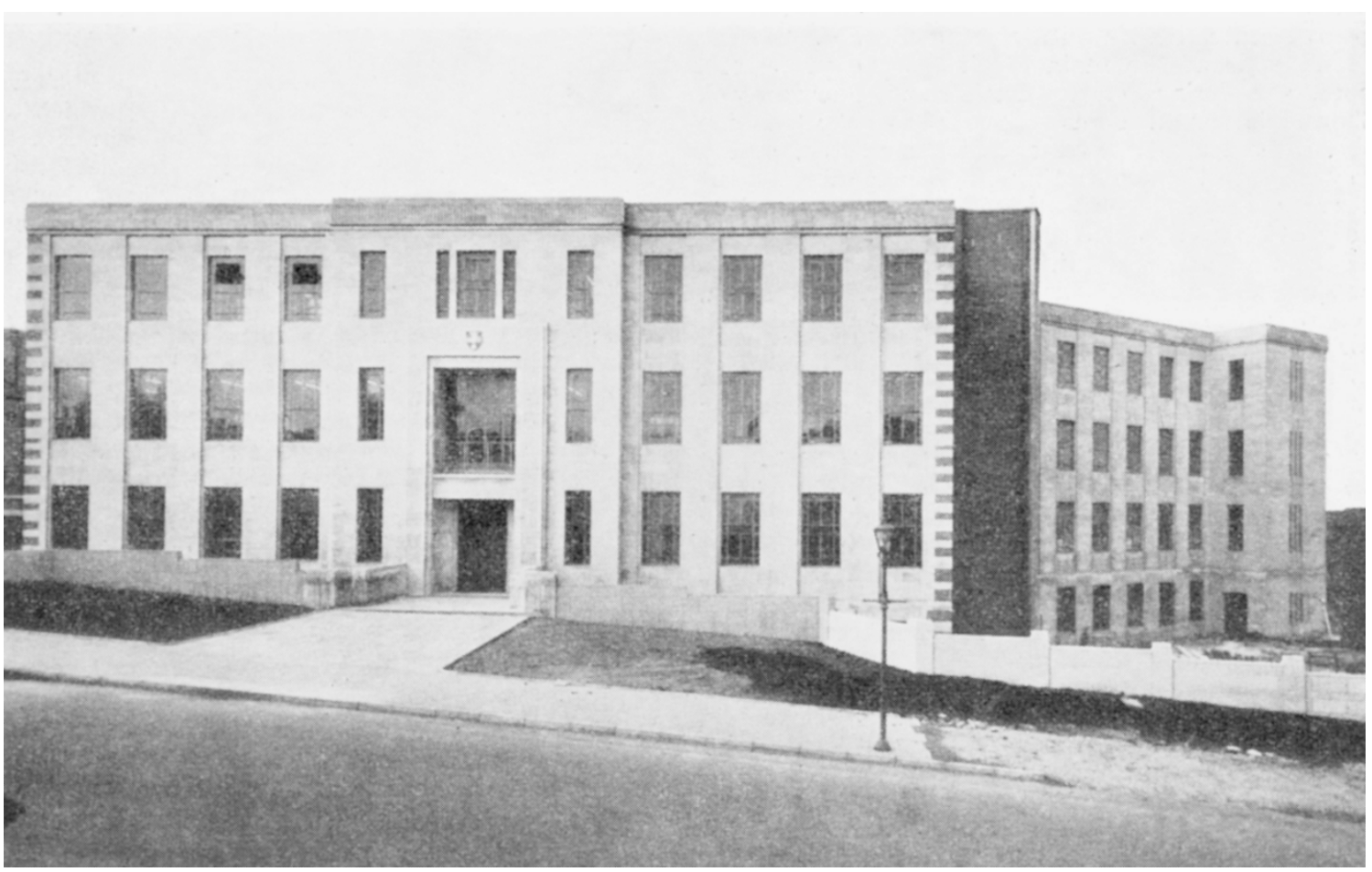

New Chemical Laboratories of the University of Sheffield 